\title{
Maternal and fetal outcome in oligohydramnios after 34 weeks of gestation
}

\author{
Mahantappa A. Chiniwar ${ }^{1}$, Joe Kaushik M. ${ }^{2}$, Sharada B. Menasinkai ${ }^{3 *}$
}

\begin{abstract}
${ }^{1}$ Department of Obstetrics and Gynecology, Adichunchanagiri Institute of Medical Sciences Hospital and Research Centre, Bellur, Karnataka, India

${ }^{2}$ Department of Fetal Medicine, Sparsh Hospital, Bangalore, Karnataka, India

${ }^{3}$ Department of Anatomy, Adichunchanagiri Institute of Medical Sciences Hospital and Research Centre, Bellur, Karnataka, India
\end{abstract}

Received: 29 August 2018

Accepted: 27 September 2018

\section{*Correspondence:}

Dr. Sharada B. Menasinkai,

E-mail: drsharadabm@gmail.com

Copyright: (c) the author(s), publisher and licensee Medip Academy. This is an open-access article distributed under the terms of the Creative Commons Attribution Non-Commercial License, which permits unrestricted non-commercial use, distribution, and reproduction in any medium, provided the original work is properly cited.

\section{ABSTRACT}

Background: Oligohydramnios is one of the major causes of maternal and perinatal morbidity and mortality. It is a clinical condition characterized by Amniotic Fluid Index (AFI) $\leq 5 \mathrm{~cm}$ by sonographic assessment. The aim of present study is to know the maternal and fetal outcome in oligohydramnios after 34 weeks of gestation compared with women who had normal volume of amniotic fluid.

Methods: Study was done for the period of 21 months from November 2014-July 2016 at Adichunchanagiri Institute of Medical Sciences, Hospital and Research Centre Bellur. 50 antenatal cases with > 34 weeks of gestation with AFI $\leq 5 \mathrm{~cm}$ by ultrasonographic estimation were included as study group and 50 women with normal AFI were included as control group. Maternal and fetal outcome of the women with oligohydramnios were analyzed and compared with control group.

Results: Results were analyzed statistically using parameters like mean, SD, Chi Sq test, P value. Amniotic fluid was clear in $32 \%$ in study and $78 \%$ in control group, thin meconium stained in $30 \%$ in study group and 14\% in control group and was thick meconium stained in $38 \%$ in study group and $8 \%$ in control group (Chi square $=22.31$, $\mathrm{p}<0.0001)$. Induction of labour was done in $54 \%$ in study group and $20 \%$ in control group. Cesarean delivery was done in $58 \%$ in study group women and $28 \%$ in control group women. Regarding the birth weight of babies $62 \%$ were $<2.5 \mathrm{~kg}$ in study group and $18 \%$ in control group with $\mathrm{p}<0.001 .10 \%$ of babies in study group required NICU admission and perinatal mortality was $2 \%$.

Conclusions: Due to increased perinatal morbidity and mortality and increased rate of LSCS, timely decision during labour is important to reduce perinatal morbidity and mortality.

Keywords: Amniotic Fluid Index (AFI), Bio Physical Profile (BPP), Intra Uterine Death (IUD), Lower segment cesarean section (LSCS), Meconium stained, Neonatal intensive care unit (NICU), Non-stress test (NST), Oligohydramnios, Premature rupture of membranes (PROM), Ultrasonography (USG)

\section{INTRODUCTION}

The fluid that collects within the amniotic cavity surrounding the embryo is called amniotic fluid. Hippocrates was the first person to attribute the development of amniotic fluid to fetal urine. Fetal urination is the major source of amniotic fluid, once the fetal kidney function begins at 10 -12 weeks. Fetal lung fluid is a minor contributor of amniotic fluid. ${ }^{1}$ Amniotic fluid volume rises progressively until 32 weeks of 
gestation. From 32 weeks to term the mean amniotic fluid volume is relatively constant about $600-800 \mathrm{ml}$. After 40 weeks there is progressive decline in amniotic fluid volume average of about $400 \mathrm{ml}$ at 42 weeks. Amniotic fluid is removed by fetal swallowing. Normal amniotic fluid volume is critical for normal fetal growth and development. ${ }^{1}$

Nature has made floating bed in the form of amniotic cavity filled with liquor amnii for the requirement of fetus for its existence and growth in sterile environment, avoidance of external injury and reduction of impact of uterine contractions. Decrease in amniotic fluid volume or oligohydramnios has been correlated with increased risk of intrauterine growth retardation, meconium aspiration syndrome, severe birth asphyxia, low APGAR scores and congenital abnormalities. Oligohydramnios is also associated with maternal morbidity in the form of increased rates of induction and/or operative interference. $^{2}$ With the help of amniotic fluid estimation by amniotic fluid index (AFI) using four quadrant technique during trans-abdominal ultrasound examination as per described by Phalan et al in 1997, better identification of fetus at risk can be done. ${ }^{2}$

Oligohydramnios is defined as AFI $\leq 5 \mathrm{~cm}$ or less than the $5^{\text {th }}$ percentile. It can occur at any time during pregnancy but is more common during the last trimester. Whenever there is continuation of pregnancy beyond 2 weeks of expected date of delivery, she may be at risk for low amniotic fluid levels since fluid can decrease by half once she reaches 42 weeks gestation. Oligohydramnios can complicate $12 \%$ of pregnancies that continue beyond 41 weeks. ${ }^{3}$ Assessment of amniotic fluid volume by ultrasonography is more reliable. It is calculated as sum of the deepest vertical dimension in each quadrant of the uterus. Oligohydramnios is associated with increased pregnancy complication, congenital anomalies and perinatal mortality. ${ }^{4}$

The sequel of long-standing oligohydramnios includes pulmonary hypoplasia, Potter's syndrome, club foot. Compression of the umbilical cord between the fetus and the uterine wall may occur during contractions or fetal movement causes severe Fetal Heart Rate (FHR) decelerations which are associated with low APGAR score and acidosis at birth, meconium staining, cesarean section and operative vaginal deliveries for fetal distress. ${ }^{5}$

The aim of the present study was to know the prevalence and risk factors in women with AFI $\leq 5 \mathrm{~cm}$ after 34 weeks of gestation and compare with control group (normal Amniotic fluid). The objectives are to study the obstetric management during antenatal, intra-natal and postnatal period and to know the fetal and maternal outcome.

\section{METHODS}

This is a prospective case control study over a period of 21 months from November 2014 to July 2016 at
Adichunchanagiri Institute of Medical Sciences Hospital and Research Centre Bellur. 50 antenatal cases with $>34$ weeks of gestation with AFI $\leq 5 \mathrm{~cm}$ by sonographic estimation were included as study group and 50 women with normal AFI $(8-24 \mathrm{~cm})$ were included as control group.

Detailed history was taken and clinical examination was done for all cases. Clinical evidence of oligohydramnios was looked for and previous obstetric and USG reports were reviewed. Only those women who remembered their last menstrual period correctly with previous 3 regular cycles and dating scan were included for the study. USG was done for all women and AFI was calculated by 4 quadrant Amniotic Fluid measurement technique.

\section{Inclusion criteria}

Women with singleton pregnancy who have completed 34 weeks and above with oligohydramnios form study group and those women with normal Amniotic fluid form control group.

\section{Exclusion criteria}

Women with gestational age $<34$ weeks and $>42$ weeks, polyhydramnios, PROM, multiple gestation, IUD, mal presentations, placenta previa, congenital anomalies were excluded from the study.

Induction of labour was done for women with high risk factors like PIH, by PGE 2 gel and accelerated with oxytocin. Spontaneous onset was allowed for women with no risk factors along with twice a week NST and weekly Biophysical profile (BPP). All cases were monitored thro continuous fetal monitoring during labour. After ARM nature of AF noted. Those who developed significant variable deceleration/ late decelerations, with or without meconium stained liquor were delivered by cesarean section. All newborn babies were seen by pediatrician.

Labour outcome of the women were recorded includes, spontaneous /induced, nature of A F, FHR tracings, mode of delivery, indication for cesarean section or instrumental delivery. Perinatal findings such as APGAR score $<7$ at $1 \mathrm{mt}$ and $5 \mathrm{mt}$, birth weight, admission to NICU, perinatal morbidity and mortality were noted.

\section{RESULTS}

Results were analysed statistically using parameters like mean, SD, Chi square test, $\mathrm{P}$ value. Study group consists of $47.8 \%$ Gr $1,52.2 \%$ Gr 2 and above and control group $52.2 \%$ Gr 1, $47.8 \%$ Gr 2 and above (Chi square=22.31, $\mathrm{p}<0.0001)$. Antenatal complications were not seen in $68 \%$ in the study group and $60 \%$ in control group. Mild pre-eclampsia was seen in $10 \%$ in study group and $20 \%$ in control group. Severe pre-eclampsia was present in $20 \%$ in study group and $10 \%$ in control group. Anemia 
was seen in $8 \%$ in control group women only. Table 1 showing the AFI in study and control groups. In the study group $72 \%$ of women had AFI below 4 .

Table 1: Amniotic fluid index in study and control group.

\begin{tabular}{|llllll|} 
AFI & $\begin{array}{l}\text { Study } \\
\text { group } \\
\text { number }\end{array}$ & $\%$ & AFI & $\begin{array}{l}\text { Control } \\
\text { group } \\
\text { number }\end{array}$ & $\%$ \\
\hline $2-3$ & 18 & 36 & $8.1-11$ & 21 & 42 \\
\hline $3.1-4$ & 18 & 36 & $11.1-14$ & 16 & 32 \\
\hline $4.1-5$ & 14 & 28 & $14.1-17$ & 13 & 26 \\
\hline & 50 & & & 50 & \\
\hline
\end{tabular}

The nature of the amniotic fluid was clear in $32 \%$ in study and $78 \%$ in control group. Amniotic fluid was thin meconium stained in $30 \%$ in study, $14 \%$ in control group and was thick meconium stained in $38 \%$ in study and $8 \%$ in control group (Chi square=22.31, $\mathrm{p}<0.0001$ ). Regarding the onset of labour, induction was done for $54 \%$ in study group and $20 \%$ in control group. Remaining $46 \%$ in study group and $80 \%$ in control group women had spontaneous onset of labour. Table 2 showing the mode of delivery, $42 \%$ in study group had vaginal delivery compared to $61 \%$ in control group (Chi square test=27.38).

Table 2: Mode of delivery.

\begin{tabular}{|lll|l|}
\hline $\begin{array}{l}\text { Mode of } \\
\text { delivery }\end{array}$ & $\begin{array}{l}\text { Study } \\
\text { group }\end{array}$ & $\begin{array}{l}\text { Control } \\
\text { group }\end{array}$ & Total \\
\hline FTND & $14(28 \%)$ & $30(60 \%)$ & $44(44 \%)$ \\
\hline FTVD & $7(14 \%)$ & $10(20 \%)$ & $17(19 \%)$ \\
\hline LSCS & $29(58 \%)$ & $10(20 \%)$ & $39(39 \%)$ \\
\hline Total & 50 & 50 & 100 \\
\hline
\end{tabular}

Incidence of LSCS in the study group was $58 \%$ and $39 \%$ in control group. This study shows that incidence of intervention is significantly more in the study group than control group with $p<0.001$. Table 3 showing the indications for cesarean delivery. Occurrence of fetal distress was more in study group than control group with $P$ value $<0.02$ which is statistically significant.

Table 3: Indications for LSCS.

\begin{tabular}{|llll|}
\hline Indications & $\begin{array}{l}\text { Study } \\
\text { group }\end{array}$ & $\begin{array}{l}\text { Control } \\
\text { group }\end{array}$ & Total \\
\hline Fetal distress & 25 & 8 & 33 \\
\hline Secondary arrest of descent & 3 & 2 & 5 \\
\hline Total & 28 & 10 & 38 \\
\hline
\end{tabular}

Table 4: APGAR score $<7$.

\begin{tabular}{|llll|}
\hline Time & Study group & Control group & P value \\
\hline 1 minute & $15(30 \%)$ & $5(10 \%)$ & 0.002 \\
\hline 5 minutes & $6(12 \%)$ & $1(2 \%)$ & 0.005 \\
\hline
\end{tabular}

Percentage of birth weight of babies in study and control group is shown in Table 5 . Birth weight $<2.5 \mathrm{~kg}$ was found in $62 \%$ in study group and $18 \%$ in control group with mean of 2.4 and 2.8 in study and control group respectively $(\mathrm{p}<0.001)$ statistically significant.

Table 5: Birth weight of the babies in study and control group.

\begin{tabular}{|llll|}
\hline Birth weight & Study group & Control group & Total \\
\hline$<2 \mathrm{~kg}$ & $9(18 \%)$ & $2(4 \%)$ & 11 \\
\hline $2.1-2.5 \mathrm{~kg}$ & $22(44 \%)$ & $7(14 \%)$ & 29 \\
\hline $2.6-3 \mathrm{~kg}$ & $15(30 \%)$ & $30(60 \%)$ & 45 \\
\hline$>3 \mathrm{~kg}$ & $4(8 \%)$ & $11(22 \%)$ & 15 \\
\hline & 50 & 50 & 100 \\
\hline
\end{tabular}

$10 \%$ of babies required NICU admission in study group in view of meconium aspiration, birth asphyxia and seizures. Neonatal death was $2 \%$ in study group. None of the babies admitted to NICU and no perinatal mortality in Control group. The $\mathrm{p}$ value showed strong significance $<0.001$.

\section{DISCUSSION}

Estimation of Amniotic Fluid volume is an integral part of antenatal surveillance. Reduced Amniotic Fluid carries an increased risk of complications during labour in high risk pregnancies. Relationship between sonography detected oligohydramnios perinatal morbidity and mortality has been well established by Manning and Platt. $^{4,6}$ In the present study oligohydramnios was observed in $47.8 \%$ in primigravida and $52.2 \%$ in gravida 2 and above. According to other studies Amany $\mathrm{H}$ et al $38 \%$ in primigravida, $58 \%$ in gravida 2 and above, Krishna $\mathrm{J}$ et al $52 \%$ in primigravida, Charu $\mathrm{J}$ et al $60 \%$ in primigravida, Kolsoum $\mathrm{R}$ et al $49 \%$ in primigravida. ${ }^{2-4,6}$ Patel $\mathrm{P}$ et al reported $58.75 \%$ in primigravida Enas $\mathrm{M}$ et al reported $58.2 \%$ in primigravida. ${ }^{7,8}$ Reddy $\mathrm{P}$ et al reported $60 \%$ in primigravida and $40 \%$ in multigravida. ${ }^{1}$ The present study in comparable with Krishna J et al. ${ }^{2}$

Manisha S et al reported $71 \%$ of oligohydramnios cases were associated with antenatal complications such as PIH $39 \%$, IUGR 29\%, PROM 15\%, Abruptio placenta 15\%, compared to $36 \%$ in control group. ${ }^{9}$ Deepika B et al reported $21 \% \mathrm{PIH}, 55 \%$ anemia. ${ }^{5}$ Reddy et al reported Anemia in $42.67 \%$, PIH in $25.33 \% .^{1}$ Veena $\mathrm{V}$ et al reported PIH in $17.07 \%$, IUGR in $46.34 \%$ in study group. ${ }^{11}$ Bhat $\mathrm{S}$ et al reported $\mathrm{PIH}$ in $33.3 \%$, post-datism in $50 \% .^{10}$ In present study $32 \%$ of oligohydramnios cases had associated complications. Manisha $\mathrm{S}$ et al stated AFI $0-2$ in $40 \%, 3-5$ in $60 \% .{ }^{9}$ Reddy $\mathrm{P}$ et al reported $60 \%$ in primigravida and $40 \%$ in multigravida. ${ }^{1}$ Present study AFI 2-3 was seen in $36 \%, 3-5$ in $64 \%$.

Manisha $\mathrm{S}$ et al reported, induction of labour in $65 \%$ in study group and $21 \%$ in control group. ${ }^{9}$ Purvi Patel et al reported induction of labour $15 \%$ in study group and $6.8 \%$ in control group and spontaneous delivery in 
remaining cases. ${ }^{7}$ In present study induction of labour was done for $54 \%$ in study group and $20 \%$ in control group. According to Charu $\mathrm{J}$ et al induction was done for $58 \%$ and spontaneous onset of labour in $28 \% .{ }^{6}$ Present study is comparable with study reported by Charu $\mathrm{J}$ et al. ${ }^{6}$

Regarding the $\%$ of vaginal delivery reported in various studies as, Charu J et al $44 \%$, Deepika B et al $53 \%$, Krishna $\mathrm{J}$ et al $58 \%$. $^{2,5,6}$ In present study $46 \%$ of study group had vaginal delivery. Percentage of LSCS reported by, Charu J et al $56 \%$, Deepika B et al $47 \%$, Krishna J et al $42 \%$. $^{2,5,6}$ Reddy $\mathrm{P}$ et al reported vaginal delivery in $38.67 \%$, LSCS in $61.33 \%$ and fetal distress was the major indication for LSCS (42.39\%). ${ }^{1}$ Veena V et al reported vaginal delivery in $62.6 \%$ and LSCS in $35.3 \%$ in women with oligohydramnios, fetal distress was indication for LSCS in $65.7 \% .{ }^{11}$ Enas $\mathrm{M}$ et al reported LSCS $63.69 \%$ in study group and $28.8 \%$ in control group. ${ }^{8}$

When authors compare incidence of vaginal delivery and LSCS with other studies, \% of LSCS was high in Purvi P et al compared with present study as seen in Table $6 .^{7}$

Table 6: Mode of delivery in study and control group.

\begin{tabular}{|c|c|c|c|c|c|c|c|c|}
\hline \multirow{2}{*}{ Mode of delivery } & \multicolumn{2}{|c|}{ Purvi P et al ${ }^{7}$} & \multicolumn{2}{|c|}{ Amany $\mathrm{H}$ et $\mathrm{al}^{3}$} & \multicolumn{2}{|c|}{ Veena $\mathbf{V}$ et al ${ }^{11}$} & \multicolumn{2}{|c|}{ Present } \\
\hline & Study & Control & Study & Control & Study & Control & Study & Control \\
\hline Vaginal delivery & $18.75 \%$ & $73.44 \%$ & $58 \%$ & $80 \%$ & $51.22 \%$ & $67.5 \%$ & $42 \%$ & $80 \%$ \\
\hline LSCS & $81.25 \%$ & $26.56 \%$ & $42 \%$ & $20 \%$ & $48.78 \%$ & $32.55 \%$ & $58 \%$ & $20 \%$ \\
\hline
\end{tabular}

In the present study baby weight was $<2 \mathrm{~kg}$ in $18 \%$ in study group and $4 \%$ in control group and $2.1-3.0 \mathrm{~kg}$ in $74 \%$ in both study and control group where as Patel $\mathrm{P}$ et al reported $5 \%$ in study group and $2.19 \%$ in control group. ${ }^{7}$ Baby weight $<2.5 \mathrm{~kg}$, was reported by Charu $\mathrm{J}$ et al $58 \%$, Kolsoum $\mathrm{R}$ et al $29 \%$, Krishna $\mathrm{J}$ et al $36 \%$, Manisha $\mathrm{S}$ et al $73 \%$ and $\mathrm{P}$ Reddy et al $48 \%$. $^{1,2,4,6,9}$ Present study is comparable with the study by Manisha $\mathrm{S}$ et al. ${ }^{9}$

In the present study APGAR score $<7$ in $30 \%$ at 1 minute, $15 \%$ at 5 minutes in study group and $10 \%$ at 1 $\mathrm{mt}, 2 \%$ at $5 \mathrm{mt}$ in control group. Reddy $\mathrm{P}$ et al reported APGAR score $<7$ at 1 minute in $33 \%$ and at 5 minutes in $20 \% .^{1}$ Veena $\mathrm{V}$ et al reported APGAR score $<7$ at 1 minute in $19.51 \%$ in study group, $7.5 \%$ in control group and at 5 minutes in $12.59 \%$ in study and $2.5 \%$ in control group. ${ }^{11}$ Enas $\mathrm{M}$ et al reported $5.59 \%$ at 1 minute and $2.05 \%$ at 5 minutes in study and $8.4 \%$ at 1 minute, $1 \%$ at 5 minutes in control group. ${ }^{8}$ Manisha $\mathrm{S}$ et al reported $55 \%$ in study, $13 \%$ in control group at 1 minute. ${ }^{9}$ Kolsoum $\mathrm{R}$ et al reported $4.7 \%$ in both groups at 5 minutes, Deepika B et al reported $17.5 \%$ at 5 minutes. ${ }^{4,5}$.

Krishna $\mathrm{J}$ et al reported $22 \%$ NICU admissions and $1 \%$ neonatal death due to septicemia. ${ }^{2}$ According to Enas M et al NICU admission was required for $7.6 \%$ in babies of study group and $6 \%$ babies of control group. ${ }^{8}$ There was 1 still birth in study group due to 2 tight cord around neck and there was no immediate neonatal death in either study or control group. ${ }^{1}$ Manisha $\mathrm{S}$ et al reported higher rates of NICU admissions, $44 \%$ in study group and $13 \%$ in control group because $57 \%$ women in study group had preterm labour. ${ }^{9}$ According to Patel $\mathrm{P}$ et al NICU admissions was $20 \%$ in study group and $18.75 \%$ in control group. ${ }^{7}$ Deepika B et al reported $36 \%$ NICU admissions and $15 \%$ perinatal mortality. ${ }^{5}$ Reddy $\mathrm{P}$ et al reported NICU admission was needed in $32 \%$ and meconium aspiration syndrome was seen in $5.33 \%$, still birth was $0.67 \%$ and perinatal death was seen in $2 \% .{ }^{1}$ In present study NICU admission was done for $10 \%$ in study group. There was $2 \%$ neonatal death in study group. None of the babies in control group admitted to NICU. Manisha $\mathrm{S}$ et al reported $16 \%$ neonatal death. ${ }^{9}$ Amany $\mathrm{H}$ et al reported $15 \%$ NICU admission in study group and $3 \%$ in control group. ${ }^{3}$ NICU admission was required in $16 \%$ in study reported by Charu $\mathrm{J}$ et al, $1 \%$ in Kolsoum $\mathrm{R}$ et al and $28 \%$ in Veena $\mathrm{V}$ et al. ${ }^{4,6,11}$

\section{CONCLUSION}

To conclude in presence of oligohydramnios a thorough evaluation for hypertension, PIH, diabetes PROM etc. should be done. An AFI $\leq 5 \mathrm{~cm}$ detected after 28 weeks was associated with adverse pregnancy outcome and poor perinatal outcome. Determination of AFI should be used as an adjunct to other fetal surveillance methods and is a valuable test for predicting fetal distress in labour requiring cesarean delivery.

Funding: No funding sources

Conflict of interest: None declared

Ethical approval: The study was approved by the Institutional Ethical Committee

\section{REFERENCES}

1. Reddy P, Pranitha P. Maternal and perinatal outcome in oligohydramnios at and after 34 weeks of gestation. IOSR J Dental Med Sci. 2018;17(2):64-8.

2. Jagatia K, Singh N, Patel S. Maternal and fetal outcome in oligohydramnios: A study of 100 cases. Hypertension. 2013;10(40):724-7. 
3. Mohamed AH. Pregnancy outcome among patients with oligohydramnios and suggested plan of action. IOSR J Nursing Health Sci. 2015;4(5):65-75.

4. Kahkhaie KR, Keikha F, Keikhaie KR, Abdollahimohammad A, Salehin S. Perinatal outcome after diagnosis of oligohydramnious at term. Iranian Red Crescent Med J. 2014;16(5).

5. Bansal D, Deodhar P. A clinical study of maternal and perinatal outcome in oligohydramnios. J Res Med Dental Sci. 2017;3(4):312-6.

6. Jandial C, Gupta S, Sharma S, Gupta M. Perinatal outcome after antepartum diagnosis of oligohydramnios at or beyond 34 weeks of gestation. JK Sci. 2007;9(4):213-4.

7. Patel PK, Pitre DS, Gupta H. Pregnancy outcome in isolated oligohydramnios at term. Ntl J Comm Med. 2015;6(2):84.

8. Musktaq E, Parveen S, Shaheen F, Jan S, Abdullah A, Lone YA. Perinatal outcome in patients with isolated oligohydramnios at term: a prospective study. J Preg Child Health. 2017;4:332.

9. Sharma M, Bhagwani DK, Chaurasia M, Jain PK. Maternal and perinatal outcome in pregnancies with oligohydramnios in third trimester. Indian J Neonatal Med Res. 2016;4(3):0001-5.

10. Bhat S, Kulkarni V. Study of effects of Oligohydramnios on maternal and fetal outcome. IJMDS. 2015;4(1):582-8.

11. Vidyasagar V, Chutani N. Fetomaternal outcome in cases of oligohydramnios after 28 weeks of pregnancy. Int J Reprod Contracept Obstet Gynecol. 2017;4(1):152-6.

Cite this article as: Chiniwar MA, Kaushik JM, Menasinkai SB. Maternal and fetal outcome in oligohydramnios after 34 weeks of gestation. Int J Reprod Contracept Obstet Gynecol 2018;7:4604-8. 